\title{
FACTORS INFLUENCING THE ISOTOPICALLY EXCHANGEABLE PHOSPHATE IN SOILS
}

\section{PART III. THE EFFECT OF TEMPERATURE IN SOME CALCAREOUS SOILS}

\author{
by P. ARAMBARRI * and O. TALIBUDEEN
}

Rothamsted Experimental Station, Harpenden, Herts. (United Kingdom)

\section{INTRODUCTION}

When results for the rate of isotopic exchange in two Rothamsted soils were analysed graphically, the total isotopically exchangeable (or 'labile') phosphate of a soil suspended in $0.02 \mathrm{M} \mathrm{KCl}$ solution was found to be subdivisible into three or four fractions depending on the rates at which these fractions exchanged isotopically with the phosphate ions in solution ${ }^{10}$; the slowly exchanging part of the isotopically active phosphate in the calcareous soil was decreased by introducing low concentrations of organic anions although its lability was increased.

We now report the rate of dissolution of the ortho-phosphate ion, the equilibrium concentration of phosphate ions in solution, the rate of isotopic exchange, and the total isotopically exchangeable phosphate at $25^{\circ}, 35^{\circ}$ and $45^{\circ} \mathrm{C}$, in four soils of similar mechanical composition but with varying amounts of calcium carbonate, total phosphorus and organic carbon.

Aslyng ${ }^{1}$ observed that with Rothamsted soils $\langle\mathrm{pH}$ range 4.5-7.5) the equilibrium phosphate concentration in 0.01 molar calcium chloride increased 1 to 2 per cent per degree centigrade as the temperature was raised from $9^{\circ}$ to $27^{\circ} \mathrm{C}$. He also showed that this effect was reversible between $0^{\circ}$ and $30^{\circ} \mathrm{C}$, suggesting that the soil phosphate does not change irreversibly within this

* Research Fellow of the Ramsay Memorial Fellowship Trust; permanent address:

Centro de Edafologia y Biologia Aplicada, Cortigo El Cuarto, Sevilla, Spain. 
temperature range. Our work is confined to the examination of calcareous soils where the presence of the ortho-phosphates of calcium will mainly contribute to the behaviour of the soil phosphate. Although much detailed work has been done on the system $\mathrm{CaO}-\mathrm{P}_{2} \mathrm{O}_{5}-\mathrm{H}_{2} \mathrm{O}$, the effect of temperature on its kinetics has not been clearly defined. The results obtained by Waring ton 11 and later Bassett ${ }^{3}$ suggested that the hydrolysis of solid calcium ortho-phosphates in aqueous suspension leads to the loss of phosphorus or calcium to the solution until a solid with a $\mathrm{Ca}: \mathrm{P}$ ratio of 1.67 is obtained. Schleede et al. ${ }^{9}$ demonstrated this clearly but they also found that dicalcium phosphate dihydrate was hydrolysed to an apatite-like material only after a prolonged hydrolysis with "hot" water. The rate of this hydrolysis increased when a critical amount of a solid calcium phosphate more basic than the dicalcium phosphate had been formed 58 . Their observations provide a logical explanation for the difference between the behaviour of phosphate-rich and phosphate-deficient calcareous soils observed in the work described below.

The kinetics of the dissolition of phosphate at a fixed volume and a constant ratio of soil: solution have not been studied, presumably because the solid phase is so complex. If, however, it is assumed that the rate-controlling process is the diffusion of ions from the surface through a constant thickness of the "saturation layer" of solution, the rate of dissolution of phosphate is proportional to the distribution of phosphate on the soil surface and to the saturation deficiency in solution. (The saturation deficiency is defined as the difference between the concentrations at saturation and at any time before saturation). A comparison of the rates of dissolution at different temperatures at the same saturation deficiency would show whether any changes occurred in the surface distribution of phosphate. We have used this concept to interpret qualitatively the differences observed between the kinetics of phosphate dissolution from phosplate-rich and phosphate-deficient calcareous soils.

Little is known about how temperature affects the isotopic exchange of phosphate ions in soils, but it is generally assumed that increasing temperature must increase the rate of isotopic exchange. Bandrenghien and Govaerts ${ }^{4}$ measured the rates of isotopic exchange of both calcium and phosphate ions in solid 'tricalcium 
phosphate' suspended in $\mathrm{CaCl}_{2}$ and $\mathrm{Na}_{2} \mathrm{HPO}_{4}$ solutions at temperatures between $18^{\circ}$ and $180^{\circ} \mathrm{C}$. They found that the rate of exchange for both ions increased to the same extent up to $60^{\circ}$, after which the rate of phosphate exchange increased continuously up to $180^{\circ}$ whereas the rate of calcium exchange increased at a rate greater than that of phosphate. They found that at temperatures greater than $60^{\circ}$ the solid phase was converted to a chlorapatite and suggested that the calcium exchanged faster because calcium ions and their supplementary chloride ions migrated into the crystalline solid (in equivalent exchange for ionic $\mathrm{Ca}(\mathrm{OH})_{2}$ ). Our work shows that in calcareous soils of low phosphate status similar discontinuously large changes occur in the rate of phosphate exchange at temperatures greater than $35^{\circ} \mathrm{C}$; presumably, they are associated with a change in the nature of the solid phosphate in the soil.

\section{MATERIALS AND METHODS}

The arable soils used are described in Table 1; soils $C$ and $D$ have a high phosphate status relative to soils $A$ and $B$. The mechanical compositions of the soils are approximately the same, the major differences being in their

TABLE 1

\begin{tabular}{|c|c|c|c|c|c|c|c|c|}
\hline \multicolumn{9}{|c|}{ Description of soils } \\
\hline $\begin{array}{c}\text { Soil } \\
\text { num- } \\
\text { ber }\end{array}$ & $\begin{array}{l}\text { Rot- } \\
\text { ham- } \\
\text { sted } \\
\text { num- } \\
\text { ber }\end{array}$ & Location and description & $\begin{array}{c}\mathrm{pH} \text { in } \\
0.02 \mathrm{~d} / \\
\mathrm{KCl}\end{array}$ & $\begin{array}{l}\text { Clay } \\
\text { con- } \\
\text { tent }\end{array}$ & $\begin{array}{c}\mathrm{CaCO}_{3} \\
\%\end{array}$ & $\begin{array}{c}\text { Or- } \\
\text { ganic } \\
\text { car- } \\
\text { bon * } \\
\%\end{array}$ & $\begin{array}{l}\text { Total ** } \\
\text { phos- } \\
\text { phorus } \\
\text { mg P } \\
\text { per cent }\end{array}$ & $\begin{array}{l}\text { Response } \\
\text { to } \\
\text { pliosphate } \\
\text { ferti- } \\
\text { lisation }\end{array}$ \\
\hline A & A 6480 & $\begin{array}{l}\text { Soke of Peterborough; } \\
\text { Light loam on Lincoln- } \\
\text { slire limestone. . . . . }\end{array}$ & 7.7 & 22.6 & 3.2 & 2.10 & 52.6 & Goorl \\
\hline B & A 8832 & $\begin{array}{l}\text { Rothamsted; Exhaustion } \\
\text { land ("Superphosphate" } \\
\text { plot). . . . . . . . }\end{array}$ & 7.6 & 19.3 & 1.5 & 1.01 & 66.2 & Moderate \\
\hline $\mathrm{C}$ & A 8867 & Rothamsted; Highfield & 6.8 & 20.3 & $<0.1$ & 3.63 & 96.4 & None \\
\hline $\mathrm{D}$ & A6491 & $\begin{array}{l}\text { Midland Agricultural Col- } \\
\text { lege Centre, Tinwell, Rut- } \\
\text { land; Medium loam on } \\
\text { Inferior Oolite. . . . }\end{array}$ & 7.9 & 18.5 & 23.1 & 2.65 & 156.0 & None \\
\hline
\end{tabular}

* By dry combustion method

** $\mathrm{By} \mathrm{HClO}_{4}$ digestion 
total phosphate and $\mathrm{CaCO}_{3}$ contents. Soils $\mathrm{C}$ and $\mathrm{D}$ contain much more phosphate than soils $\mathrm{A}$ and $\mathrm{B}$.

The methods used were similar to those already described $10 ; 0.5 \mathrm{~g}$ of the soil was shaken continuously with $100 \mathrm{ml}$ of $0.02 \mathrm{M} \mathrm{KCl}$ at constant temperature and the phosphate dissolved from the soil was determined at suitable intervals. The suspension was labelled with "carrier-free" * P32 when the initial rapid rise in phosphate concentration had ended. The total phosphate and $\mathrm{P}^{32}$ concentration in solution were measured at suitable times until the specific activity in solution was constant within experiniental error. Care had to be taken with centrifugation at high speeds when separating the soil and the solution to keep the system at chemical equilibrium at the time of sampling. The whole sampling procedure required about 15 minutes.

\section{RESULTS}

Preliminary experiments on the rate of dissolution of phosphate and its temperature dependence

The general pattern for the rate of dissolution of phosphate ions

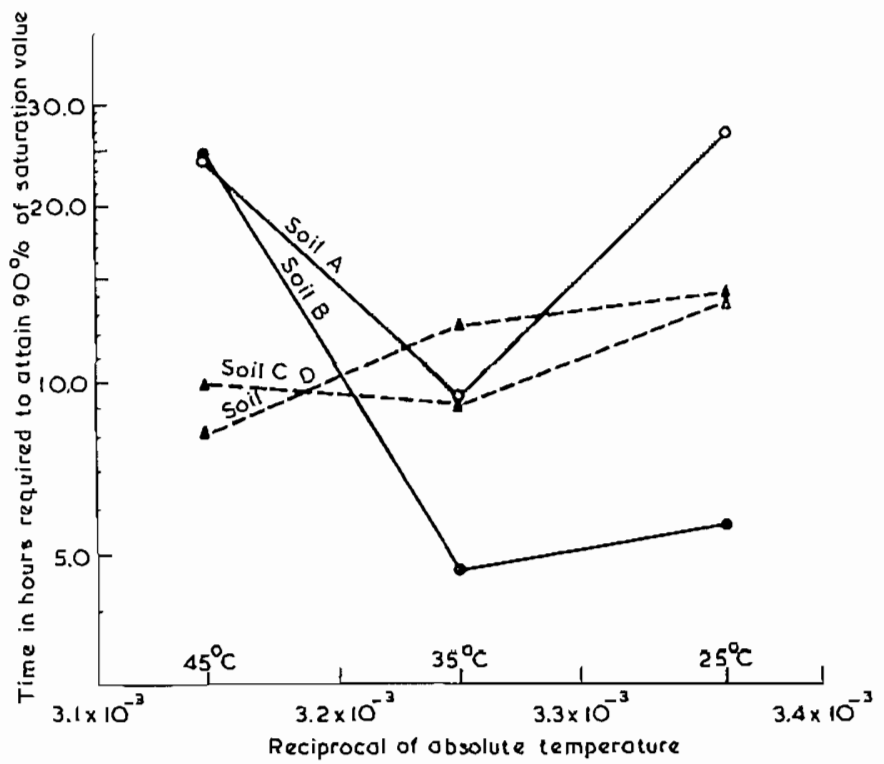

Fig. 1. Influence of temperature on the rate of dissolution of phosphate from $0.5 \mathrm{~g}$ soil in $100 \mathrm{ml} 0.02 \mathrm{M} \mathrm{KCl}$.

Low P status _-_. High P status - - - - .

* The term "carrier-free" implies that the phosphate concentration of the radioactive solution added was too small to change the phosphate concentration of the soil solution measurably. 
for these soils exhibited two characteristics - an initial rapid increase with time in the phosphate removed from the soil, followed by a slow increase or a slow decrease at longer times. Soils $A$ and $B$, with low total phosphate, showed a slight increase, which was little affected by temperature. It is assumed here that the rapid increase with time corresponds to a true dissolution and the subsequent behaviour comes from secondary unspecified reactions. The time when the rapid increase ends was estimated graphically, and the amount of phosphate dissolved at this time was taken as the saturation value for the "true dissolution" process. This saturation point was attained more rapidly as the temperature was raised from $25^{\circ}$ to $35^{\circ} \mathrm{C}$ but the behaviour of the soils at $45^{\circ} \mathrm{C}$ varied according to their phosphate content. In Figure 1, the logarithm of the time required for the $90 \%$ saturation value (or $10 \%$ saturation deficiency) to be reached is plotted against the reciprocal of the absolute temperature. Soils A and B show a decrease in the rate of dissolution (corresponding to an increase in the time required for $90 \%$ exchange) above $35^{\circ} \mathrm{C}$ unlike soils $\mathrm{C}$ and $\mathrm{D}$ which contain much more phosphate; thus soil $\mathrm{C}$ does not show any change in the rate of dissolution between $35^{\circ}$ and $45^{\circ} \mathrm{C}$, and soil $\mathrm{D}$, with a considerably higher $\mathrm{P}$ reserve, shows a normal increase in the rate of dissolution with temperature.

\section{Influence of temperature on the equilibrinm concentration of phosphate} in the soil solution

The only systematic observations on the influence of temperature on the equilibrium concentration of phosphate in the soil solution in the literature appear to be those of Aslyng ${ }^{1}$ already referred to. These show that in Rothamsted soils there is a regular and reversible increase of 1 to 2 per cent per degree centigrade in the phosphate concentration with increasing temperature in the range $0^{\circ}$ to $30^{\circ} \mathrm{C}$. In Figure 2, the logarithm of the equilibrium of phosphate concentration is plotted against the reciprocal of the absolute temperature, which shows an almost linear increase from $25^{\circ}$ to $45^{\circ}$ in soils $C$ and $D$ of high $P$ status. However, the percentage increase with soil $C$ is much greater than that found by Aslyng, presumably because it contains much organic matter. With soils $\mathrm{A}$ and $\mathrm{B}$ of low P status, the observed increase between $25^{\circ}$ and $35^{\circ}$ is within the limits observed by Aslyng; between $35^{\circ}$ and 
$45^{\circ}$, the phosphate concentration increases abnormally, suggesting a change in the nature of the solid phosphate phase.

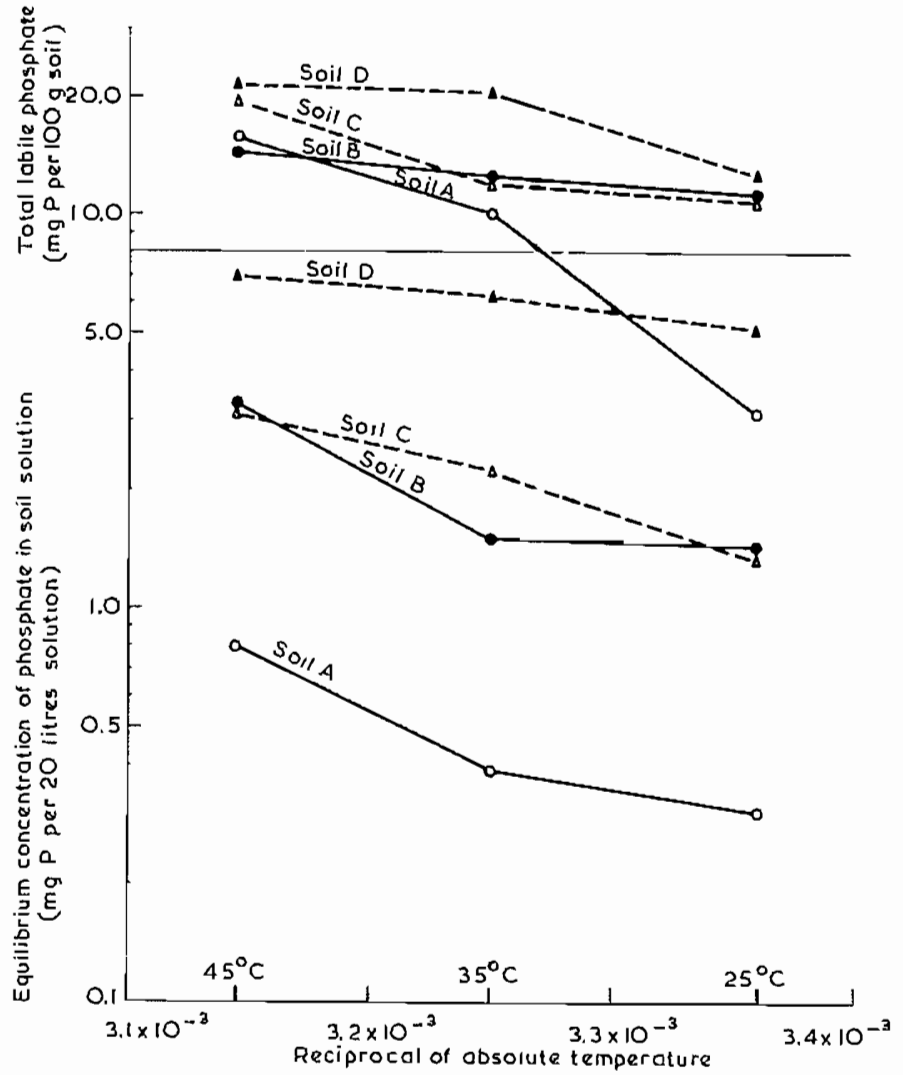

Fig. 2. Influence of temperature on the total labile phosphate and the equilibrium concentration of phosphate in the soil solution.

Low P status —_, High P status -....

\section{Influence of temperature on the total labile phosphate}

The total labile phosphate in all the soils increases with temperature (Figure 2) and, except for soil $A$, this increase is relatively small and regular between $25^{\circ}$ and $45^{\circ}$. The total labile phosphate in soil $\mathrm{A}$, which has the lowest phosphate content of the four soils, increases considerably but fairly regularly in this temperature range. Apart from this, soils of low and high phosphate status show no clear difference in the behaviour of their total labile phosphate. 
The labile phosphate can be sub-divided into the 'instantaneous', 'rapid', 'medium' and 'slow' components as described previously 10 . The influence of temperature on the distribution of these components shows the following trends:

(1) As the temperature of exchange is increased, it becomes increasingly difficult to separate the 'instantaneous' and 'rapid' exchanging components; these are, therefore, referred to here as a single 'rapid' exchanging component.

(2) The increase in the total labile phosphate and the phosphate in solution is reflected in a corresponding increase in the 'rapid' component.

(3) The magnitude of the 'medium' component is always very small and does not show any regular alteration with temperature.

4() The 'slow' component, however, is always large and tends to decrease with increasing temperature except in soil A, which shows a large increase as the temperature is raised from $35^{\circ}$ to $45^{\circ} \mathrm{C}$.

\section{Influence of temperature on the rate of isotopic exchange}

As shown previously ${ }^{10}$, the rate of isotopic exchange is best represented by a rate constant from the relation:

$$
R_{x}=\frac{0.693}{t_{\frac{1}{x}}} \cdot \frac{P_{x} \cdot P_{s s}}{P_{x}+P_{s s}}
$$

where $P_{x}$ is the isotopically-exchangeable phosphorus in the 'rapid', 'medium' and 'slow' exchanging components respectively of the labile phosphate $P_{s}$ in the soil, $P_{s s}$ is the phosphate in solution and $t_{\frac{1}{2}}$ is the half-time of exchange graphically determined from the linear variation of the logarithm of the fractional exchange with time.

Thus $P_{s}=P_{1}+P_{2}+P_{3}$ and the total labile phosphate $P_{e}=P_{s}+P_{s s}$.

Table 2 shows the influence of temperature on the magnitudes and the rate of exchange of the 'rapid', 'medium' and 'slow' components for four soils. These results clearly illustrate (1) the increase in the rates of exchange with temperature, (2) the difference in the behaviour of soils of low and high phosphate status between $35^{\circ}$ and $45^{\circ} \mathrm{C}$.

The rate of the 'rapid' exchange is usually too fast to measure accurately. The magnitude of the 'rapid' component increases 
TABLE 2

Influence of temperature on the components of the total labile phosplate in four soils (Magnitude of components in $\mathrm{mg} P$ per $100 \mathrm{~g}$ soil: Rates $R_{x}$ in mg $P$ per $100 \mathrm{~g}$ soil per hour)

\begin{tabular}{|c|c|c|c|c|c|c|c|c|c|}
\hline \multirow[b]{2}{*}{$\begin{array}{l}\text { Component of } \\
\text { total labile phosphate }\end{array}$} & \multirow[b]{2}{*}{ 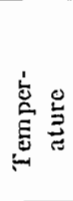 } & \multicolumn{2}{|c|}{ Soil A } & \multicolumn{2}{|c|}{ Soil B } & \multicolumn{2}{|c|}{ Soil C } & \multicolumn{2}{|c|}{ Soil D } \\
\hline & & 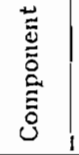 & 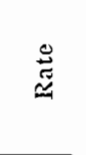 & 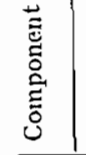 & $\stackrel{\stackrel{\leftrightarrows}{\Xi}}{\cong}$ & 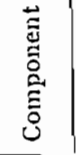 & $\stackrel{0}{\stackrel{0}{*}}$ & 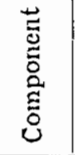 & 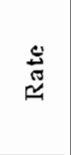 \\
\hline \multirow[t]{3}{*}{ 'Rapid' $P_{1} \ldots$. . . . . . . } & $25^{\circ}$ & 0.81 & * & 1.69 & * & 1.94 & * & 0.86 & 0.84 \\
\hline & $35^{\circ}$ & 3.17 & * & 2.22 & * & 4.62 & * & 4.54 & 2.53 \\
\hline & $45^{\circ}$ & 4.34 & * & 8.49 & * & 8.44 & * & 6.42 & 2.23 \\
\hline \multirow{3}{*}{ 'Medium' $P_{2} \ldots \ldots$} & $25^{\circ}$ & 0.10 & 0.011 & 0.43 & 0.070 & 0.42 & 0.022 & 1.04 & 0.18 \\
\hline & $35^{\circ}$ & 0.12 & 0.053 & 0.48 & 0.047 & 0.21 & 0.048 & 2.82 & 0.45 \\
\hline & $45^{\circ}$ & 0.33 & 0.089 & 0.39 & 0.215 & 1.21 & 0.177 & 1.91 & 0.34 \\
\hline \multirow[t]{3}{*}{ 'Slow' $P_{3} \ldots$. . . . . . . . . . } & $25^{\circ}$ & 2.10 & 0.0035 & 7.74 & 0.021 & 8.16 & 0.013 & 8.72 & 0.046 \\
\hline & $35^{\circ}$ & 6.31 & 0.015 & 8.04 & 0.027 & 6.15 & 0.079 & 8.34 & 0.078 \\
\hline & $45^{\circ}$ & 10.50 & 0.116 & 2.99 & 0.139 & 7.25 & 0.069 & 7.25 & 0.092 \\
\hline \multirow[t]{3}{*}{ Total in soil $P_{s}, \ldots$} & $25^{\circ}$ & 3.01 & - & 9.86 & - & 10.52 & - & 10.62 & - \\
\hline & $35^{\circ}$ & 9.60 & - & 10.74 & - & 10.98 & - & 15.70 & - \\
\hline & $45^{\circ}$ & 15.17 & - & 11.87 & - & 16.90 & - & 15.58 & - \\
\hline \multirow[t]{3}{*}{$P$ in solution $P_{s s}$ at time of tagging } & $25^{\circ}$ & 0.15 & - & 1.65 & - & 0.80 & - & 2.04 & - \\
\hline & $35^{\circ}$ & 0.44 & - & 1.74 & - & 1.34 & - & 4.96 & - \\
\hline & $45^{\circ}$ & 0.55 & - & 2.69 & 一 & 2.58 & - & 5.08 & - \\
\hline \multirow[t]{3}{*}{ Total Inbile $P_{e}$ phosphate . . } & $25^{\circ}$ & 3.16 & - & 11.51 & - & 11.32 & - & 12.66 & - \\
\hline & $35^{\circ}$ & 10.04 & - & 12.48 & 一 & 12.32 & - & 20.66 & - \\
\hline & $45^{\circ}$ & 15.72 & - & 14.56 & - & 19.48 & - & $2 t .66$ & - \\
\hline
\end{tabular}

* The rate of exchange was too fast to be measured reliably.

gradually in all the soils between $25^{\circ}$ and $45^{\circ}$ and no clear distinction can be drawn between soils of low and high phosphate status. This is parallel to the behaviour of the total labile phosphate described earlier.

The magnitude of the 'medium' component is invariably very small and in general shows little significant change with temperature. The rate of exchange, however, shows an abnormal increase with soils $\mathrm{A}$ and $\mathrm{B}$ between $35^{\circ}$ and $45^{\circ} \mathrm{C}$.

The 'slow' component $\mathrm{P}_{3}$ always forms a significant part of the labile phosphate. Its magnitude does not vary appreciably with temperature with soils $C$ and $D$ of high phosphate status but in soil $\mathrm{A}, \mathrm{P}_{3}$ increases considerably between $25^{\circ}$ and $45^{\circ}$ in contrast 


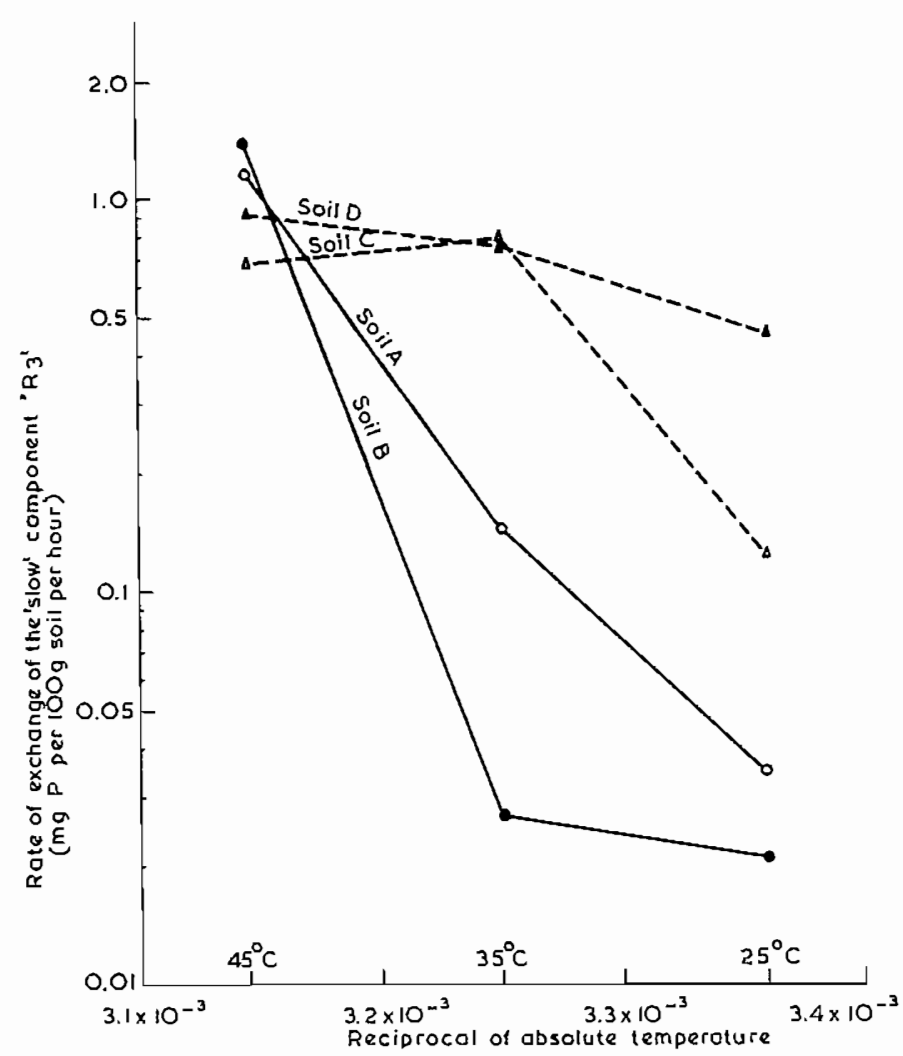

Fig. 3. Influence of temperature on the rate of exchange of the 'slow' component ' $R_{3}$ '.

Low P status —_- High P status - - - - .

with the behaviour of $\mathrm{P}_{3}$ in soil $\mathrm{B}$. The rate constant for the 'slow' exchange (Table 2 and Figure 3 ) for all soils between $25^{\circ}$ and $35^{\circ} \mathrm{C}$, and for soils $C$ and $D$ from $35^{\circ}$ to $45^{\circ}$, increases slightly. Soils $A$ and $B$, however, show a very sharp increase in the rate constant between $35^{\circ}$ and $45^{\circ}$, although the magnitudes of their 'slow' components differ vastly. The rate constants at $45^{\circ}$ in soils $\mathrm{A}$ and $\mathrm{B}$ of low $\mathrm{P}$ status are of the same order $\langle 0.116$ and $0.139 \mathrm{mg} P$ per $100 \mathrm{~g}$ soil per hour) and are significantly greater than those in soils $C$ and D (0.069 and $0.092 \mathrm{mg} P$ per $100 \mathrm{~g}$ soil per hour) of high $\mathrm{P}$ status. 


\section{DISCUSSION}

The principal teature of these results is the difference in the behaviour of soils of low and high phosphate status between $35^{\circ}$ and $45^{\circ} \mathrm{C}$. Thus, with soils $\mathrm{A}$ and $\mathrm{B}$, the effect of temperature on the rates of dissolution, on the equilibrium concentration of phosphate, and on the rate of exchange for the 'slow' components, suggests the conversion of their 'slow' component into a new phosphate phase.

The inorganic phosphate in calcareous soils in aqueous suspension thus seem to be in two distinct parts - a small but nevertheless important amount, which is rapidly labile, is probably associated with the surfaces of the clay and to a lesser extent with the calcium carbonate surfaces; the remainder, which exchanges slowly, consists of a mixture of the insoluble orthophosphates of calcium whose composition, and hence whose subsequent behaviour, depends on the conditions under which they were precipitated. Although the nature of these calcium phosphates must be independent of the amount of $\mathrm{CaCO}_{3}$, they must be intimately associated physically with the calcium carbonate in the soil which is the source of the calcium concentration in the soil solution. The amount of $\mathrm{CaCO}_{3}$ in the soil must thus control the amount of the insoluble calcium orthophosphate formed. The nature of these phosphates depends on the activity of calcium and phosphate ions in solution, the former being almost independent of the amount of $\mathrm{CaCO}_{3}$ present. In phosphate-rich calcareous soils, where the activity ratio $A_{\mathrm{Ca}}: A_{\mathbf{P}}$ is low, the principal component of the precipitated phase will be dicalcium phosphate contaminated with a calciumdeficient apatite (i.e. an apatitic structure with an atomic ratio $\mathrm{Ca}: \mathrm{P}$ less than 1.67) whose amount and nature will depend on the amount of the soluble phosphate added initially to the soil. These results suggest that in such soils ( $C$ and D) this apatite is less than the critical amount suggested by the work of Buch 5 and Sanforche and Henry ${ }^{8}$; accordingly the rate of hydrolysis of the dicalcium phosphate to an apatite phase is very small and is indeed not measurable in our experiments. The reverse holds for the phosphate-deficient soils $\mathrm{A}$ and $\mathrm{B}$ where the clearly measurable changes in the slowly labile phosphate with temperature point to the rapid hydrolysis of the precipitated calcium phosphates and

Plant and Soil 
the presence of a much higher proportion of a calcinnn-deficient apatite, which is rapidly hydrolysed at higher temperatures to a true apatite with the consequent production of a phosphate-rich solution. It follows that, when the phosphate activity in the soil solution is continuously depleted by some external agency (e.g. by plant roots or by continuous rapid leaching), the nature of the dicalcium phosphate residue in phosphate-rich calcareous soils will not be significantly affected until it is decreased to a very small proportion. By contrast, in a phosphate-deficient soil, such a process will considerably hasten the hydrolysis of the calciumdeficient apatite to a much less labile true apatite.

Aslyng ${ }^{2}$ suggested that some calcareous Rothamsted soils contain octocalcium phosphate ${ }^{5}$. The hydrolysis of octocalcium phosphate at high temperatures leads to the formation of hydroxyapatite and dicalcium phosphate, probably according to

$$
2 \mathrm{Ca}_{4} \mathrm{H}\left(\mathrm{PO}_{4}\right)_{3}+\mathrm{H}_{2} \mathrm{O} \rightarrow \mathrm{Ca}_{5}\left(\mathrm{PO}_{4}\right)_{3} . \mathrm{OH}+3 \mathrm{CaHPO}_{4}
$$

Octocalcium phosphate is itself produced by the hydrolysis of dicalcium phosphate and a cyclic process can be imagined in which the octocalcium phosphate residues in the soil are progressively converted to hydroxyapatite. Until this conversion is nearly complete, the more soluble dicalcium phosphate may govern the 'quasi-equilibrium' concentrations in the soil solution and cause the abnormal behaviour of calcareous soils of low $\mathrm{P}$ status.

The presence of potassium chloride offers another explanation of this behaviour in soils $A$ and $B$. The chloride ion diffuses fairly readily at elevated temperatures as a counter-ion (Bandrenghien and Govaerts ${ }^{4}$ ) or in isomorphous substitution (for $\mathrm{OH}$-ions) into apatite or pseudoapatite type of phosphates to form a chlorapatite-like phosphate (Bjerrum ${ }^{5}$ ) with greatly increased solubility and lability. It is significant that soils $C$ and $D$ (the latter having 23 per cent calcium carbonate) show no signs of this behaviour, which suggests that if they contain any apatite-like or allied phosphates these cannot be detected in the 'labile' phosphate, and that their behaviour is masked by that of phosphate compounds of higher energy content.

The increased uptake of phosphorus by plant roots at elevated temperatures has been ascribed (Zhurbitzky and Shtrausberg?) to increased plant-physiological activity in the roots as well as 
in the tops of plants. It is clear from this work that the higher rates of dissolution and the higher equilibrium concentrations in the soil as well as an increased rate of turnover of the labile phosphate in the soil may, at least, be equally responsible for increased phosphate uptake.

The turnover of the 'slow' component in soils of high $\mathrm{P}$ status is 5 to 10 times faster than in soils of low $\mathrm{P}$ status at $35^{\circ} \mathrm{C}$; but at $45^{\circ} \mathrm{C}$, the situation is reversed, the rates in the low-phosphate soils being $1 \frac{1}{2}$ to 2 times higher than in soils of high $\mathrm{P}$ status. This suggests that an abnormally high uptake of phosphate may be realised from calcareous soils of low phosphate status et temperatures above $35^{\circ} \mathrm{C}$.

\section{SUMMARY}

The influence of temperature in the range $25^{\circ}$ to $45^{\circ} \mathrm{C}$ on the rate of dissolution and the equilibrium concentration of phosphate, on the labile phosphate and its components, and on the rates of isotopic exchange in four soils with varying $\mathrm{CaCO}_{3}$ contents and phosphate status was investigated. There were abnormal increases in the equilibrium phosphate concentration and the rate of exchange of the slowly labile phosphate of soils of low $P$ status between $35^{\circ}$ and $45^{\circ}$. The slowly exchanging component normally constitutes the greater part of the labile phosphate of the soil. The soils of higher phosphate status, irrespective of their $\mathrm{CaCO}_{3}$ content, did not show this abnormal behaviour. The observed difference is connected with the nature and the composition of the basic calcium phosphates associated with the soil calcium carbonate.

Received July 23, 1959

\section{REFERENCES}

I Aslyng, H. C., The lime and phosphoric acid potentials of soils, their determination and practical applications. Pl. D. Thesis. University of London. 41-44. (1950).

2 Aslyng, H. C., The lime and phosphate potentials of soils; the solubility and availability of phosphate. Roy. Vet. Agr. Col. Copenhagen Den. Yearbook 195x, 1-50 (1954).

3 Bassett, H., Jr., The phosphates of calcium, Part IV, The basic plosphates. J. Chein. Soc. 3, 620-642 (1917).

4 Baudrenghien, A. and Govaerts, J., Lichanges isotopiques et structure du phosphate tricalcique. III. Application de la loi de Boltzmann. IUPAC, Colloquium Munster West, 2-6 Sept. 1954, 212-216 (1954).

5 Buch, K., Die Zersetzung des Dicalciumphosphats durch Wasser. Z. Anorg. Chem. 52, 325-341 (1907).

6 Bjerrum, N., Calcium phosphate I. The solid calcium-orthophosphates. Kgl. Danske Videnskab. Selskab Mat. Fys. Medd. 31 no. 7, 1-68 (1958). 
7 Brown, W. E., Lehr, J. R., Smith, J. P., and Frazier, A. W., Crystallograplyy of octo-calcium plosphate. J. Amer. Chem. Soc. 79, 5318 (1957).

8 Sanforche, A. and Henry, J, Action of water on dicalcium phosphate. Compt. Rend. 19), 1940-2 (1932).

9 Schleede, A., Schmidt, W., and Kindt, HI., Calcium phosphates and apatites. Z. Elektrochem. 38, 633 (1932).

10 Arambarri, P., and Talibudeen, O., Factors influencing the isotopically exchangeable phosphate in soil. Part I. The effect of low concentrations of organic anions. Plant and Soil 11, 343-354 (1959).

11 Warington, R., On the decomposition of tricalcic plosphate by water. J. Chem. Soc. 26,983 (1873).

12 Zhurbitsky, Z. I., and Shtrausberg, D. V., The influence of temperature on the mineral assimilation of plants. Proc. UNESCO Intern. Conf. Radioisotopes in Sci. Research Paris 1957 (in the press) (1959). 